\title{
Microcalorimetry studies of the antimicrobial actions of Aconitum alkaloids"
}

\author{
Yan-bin SHI ${ }^{1}$, Lian LIU $^{2}$, Wei SHAO ${ }^{3}$, Ting WEI ${ }^{3}$, Gui-mei LIN ${ }^{\dagger \$ 3}$ \\ $\left({ }^{1}\right.$ School of Mechanical and Automotive Engineering, Qilu University of Technology, Jinan 250353, China) \\ ( ${ }^{2}$ Beijing Health Vocational College, Beijing 100053, China) \\ $\left({ }^{3}\right.$ School of Pharmaceutical Science, Shandong University, Jinan 250012, China) \\ †E-mail: guimeilin@sdu.edu.cn \\ Received May 18, 2015; Revision accepted July 22, 2015; Crosschecked July 24, 2015
}

\begin{abstract}
The metabolic activity of organisms can be measured by recording the heat output using microcalorimetry. In this paper, the total alkaloids in the traditional Chinese medicine Radix Aconiti Lateralis were extracted and applied to Escherichia coli and Staphylococcus aureus. The effect of alkaloids on bacteria growth was studied by microcalorimetry. The power-time curves were plotted with a thermal activity monitor (TAM) air isothermal microcalorimeter and parameters such as growth rate constant $(\mu)$, peak-time $\left(T_{\mathrm{m}}\right)$, inhibitory ratio $(I)$, and enhancement ratio $(E)$ were calculated. The relationships between the concentration of Aconitum alkaloids and $\mu$ of $E$. coli or $S$. aureus were discussed. The results showed that Aconitum alkaloids had little effect on $E$. coli and had a potentially inhibitory effect on the growth of $S$. aureus.
\end{abstract}

Key words: Aconitum alkaloids, Escherichia coli, Staphylococcus aureus, Microcalorimetry doi: 10.1631 /jzus.B1500121

Document code: A

\section{Introduction}

Radix Aconiti Lateralis (RAL) (also known as monkshood or aconite), which is the daughter root of Aconitum carmichaeli Debx. (Ranunculaceae), is one of the most useful herbal medicines. It has been reported that RAL Preparata have some pharmacological activities for the treatment of heart failure, congestion, colds, neuralgia, polyarthralgia, rheumatism, and gout (Wadsö, 2002; Zhao et al., 2006; Chen et al., 2008). Up until now, the most investigated pharmaceutical ingredients in RAL Preparata were a series of alkaloids, which are also found to be the major toxic ingredients in the medicine. Inappropriate use of RAL Preparata could result in unwarranted toxicity (Ameri,

\footnotetext{
ॠ Corresponding author

* Project supported by the National Natural Science Foundation of China (No. 21203112) and the Natural Science Foundation of Shandong Province (No. ZR2012BQ002), China

(b) ORCID: Gui-mei LIN, http://orcid.org/0000-0002-3795-7012

(c) Zhejiang University and Springer-Verlag Berlin Heidelberg 2015
}

1998; Singhuber et al., 2009; Wang et al., 2009). However, there are few studies on the effect of alkaloids on bacteria. Therefore, the aim of this study is to investigate the effect of alkaloids extracted from RAL Preparata on bacteria.

In recent years, microcalorimetric techniques have been widely applied in biochemistry, biophysics and other fields (Wadsö, 1995; 1997; 2001). These techniques have also increasingly been used to study the interactions between drugs and microorganisms. Microcalorimetry is a highly sensitive, quantitative, and versatile tool for assessing the activity of microorganisms. Further advantages of this method are that it is simple and non-invasive vis-a-vis the sample. As a result, the power-time curves of bacteria can be continuously plotted in real time (Critter et al., 2001; Yan et al., 2007). It can provide abundant thermodynamic and kinetic information, such as the growth rate constant $(\mu)$, inhibitory ratio $(I)$, generation time $(T)$, minimal inhibitory concentration (MIC), peakheight $\left(H_{\mathrm{m}}\right)$, peak-time $\left(T_{\mathrm{m}}\right)$, and total heat $\left(Q_{\mathrm{tot}}\right)$. 
Microcalorimetry therefore appears to be a suitable technique for studying microbial activity (Xi et al., 2002; Wu et al., 2005).

In this paper, we investigate the antimicrobial activity of alkaloids extracted from RAL Preparata on Escherichia coli and Staphylococcus aureus growth using microcalorimetry. Aconitum alkaloids were obtained using the water extraction method and determined with aconitine reference substance by ultraviolet (UV). The metabolic power-time curves for $E$. coli and $S$. aureus growth in different concentrations of extractions were obtained and compared with bacterial growth curves without the addition of samples. The relationships between the thermokinetic parameters of $E$. coli growth and sample concentrations were discussed, and the correlations between the antimicrobial effects were determined.

\section{Materials and methods}

\subsection{Instrumentation}

A thermal activity monitor (TAM) air device (Thermometric AB, Sweden), an 8-channel heatconduction calorimeter for heat-flow measurements in isothermal conditions, was used to assess the metabolism of E. coli and $S$. aureus. The device was equipped with eight twin calorimetric channels with one side for the sample and the other for a static reference. Measurements were made in sealed 24-ml glass ampoules between $5{ }^{\circ} \mathrm{C}$ and $90^{\circ} \mathrm{C}$. The error in the temperature measurements was $\pm 0.02{ }^{\circ} \mathrm{C}$. The detection limit was $2 \mu \mathrm{W}$ and the baseline stability was $2 \times 10^{6} \mu \mathrm{W}$ over a period of $24 \mathrm{~h}$ (Kong et al., 2008). The heat output was recorded continuously using a PLW32 recorder in real time.

\subsection{Materials and methods}

The bacteria E. coli $(\mathrm{CMCC}(\mathrm{B}) 44102)$ and $S$. aureus (CMCC(B)26003) were provided by the Shandong Institute for Drug Control, China. They were routinely cultured in a Luria-Bertani (LB) culture medium, which contained $10 \mathrm{~g}$ of peptone, $5 \mathrm{~g}$ of yeast extract, and $5 \mathrm{~g}$ of $\mathrm{NaCl}$ per liter ( $\mathrm{pH} 7.0-7.2$ ). The LB culture medium was sterilized by autoclaving at $121^{\circ} \mathrm{C}$ for $20 \mathrm{~min}$. The Aconitum alkaloids were provided by Jiangyou Zhongba Ltd. (Sichuan, China).

The purified Aconitum alkaloid test samples were prepared according to the following procedure. The powdered commercial RAL Preparata $(10.0 \mathrm{~g})$ was extracted at boiling conditions with 180 and $90 \mathrm{ml}$ of water. The combined filtrates were concentrated to approximately $120 \mathrm{ml}$ by rotary vacuum evaporation. The concentrated filtrate was then fractionated overnight with $60 \%$ ethanol at $4{ }^{\circ} \mathrm{C}$. The supernatant was concentrated and extracted with chloroform five times to obtain the Aconitum alkaloids, which were then dried under vacuum. The average yield of Aconitum alkaloids was determined by UV spectroscopy at $490 \mathrm{~nm}$. According to the standard curve established by the aconitine reference substance $(A=0.0181 c+0.1353, r=0.9989$, where $A$ is the absorbance and $c$ is the concentration of aconitine reference substance), the content of Aconitum alkaloids in RAL Preparata was $81.2 \%$.

The microcalorimetric measurements were made with the ampoule method. The LB culture medium containing the bacteria was placed in 20-ml glass ampoules. Then, different concentrations of Aconitum alkaloids were mixed into each ampoule to a final volume of $10 \mathrm{ml}$. One ampoule without Aconitum alkaloids was used as the blank control. The ampoules were then sealed and placed in the microcalorimeter. The temperature was maintained at $37^{\circ} \mathrm{C}$. The powertime signals were recorded every minute until the recordings returned to the baseline measurement (Yang et al., 2008).

\section{Results and discussion}

\subsection{Power-time curves}

The power-time curves of the growth of $E$. coli and $S$. aureus without Aconitum alkaloids are shown in Figs. 1 and 2. The shapes of the two curves are different. The E. coli growth curves can be divided into four stages: the first growth, first decrease in metabolic activity, second growth, and second decrease in metabolic activity stages. The output power was stronger than that of $S$. aureus in the first $30 \mathrm{~min}$. The power-time curves of the $S$. aureus growth process were comparatively simple with only an increased growth stage and a decreased metabolic stage. In the exponential phase (the first rapid growth stage), the bacteria were in a good environment with sufficient nutrients and limited metabolic products. The shapes 


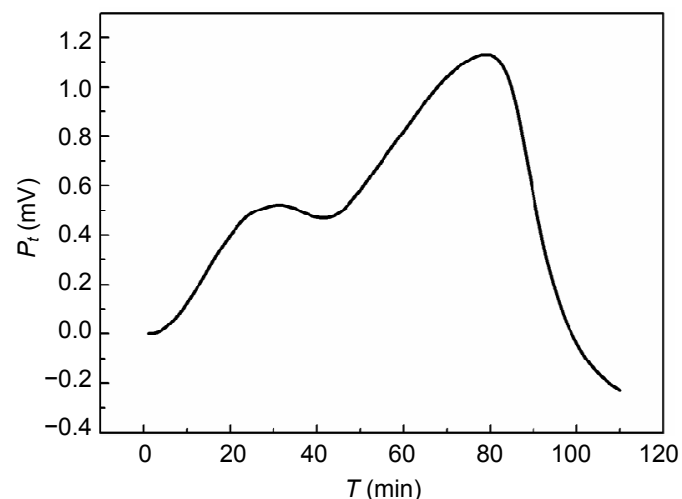

Fig. 1 Power-time curve of $E$. coli without Aconitum alkaloids

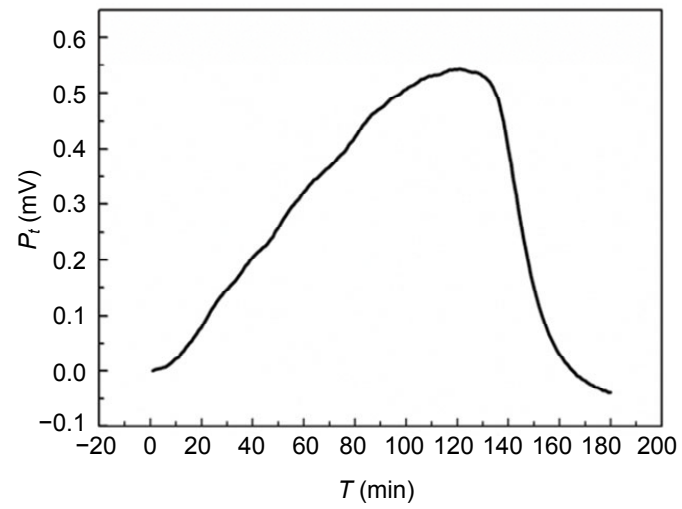

Fig. 2 Power-time curve of $S$. aureus without Aconitum alkaloids

of the power-time curves made it possible to study the effect of drugs on the bacteria. The exponential growth phases of E. coli and $S$. aureus with the addition of different concentrations of Aconitum alkaloids are shown in Figs. 3 and 4, respectively. In the exponential growth phase, $S$. aureus had a distinct downward trend with increases in the Aconitum alkaloid concentrations, and a high concentration of samples needed more time to reach the same heat output. However, a concentration-dependent delay was not clearly observed in the exponential growth phases of E. coli with the Aconitum alkaloid samples.

\subsection{Thermokinetics}

In the exponential growth phase, the power-time curves for E. coli and S. aureus obey the following law:

$$
\mathrm{d} N_{t} / \mathrm{d} t=\mu N_{t}-\beta N_{t}^{2}
$$

where $N_{t}$ is the bacterial number at time $t, \mu$ is the

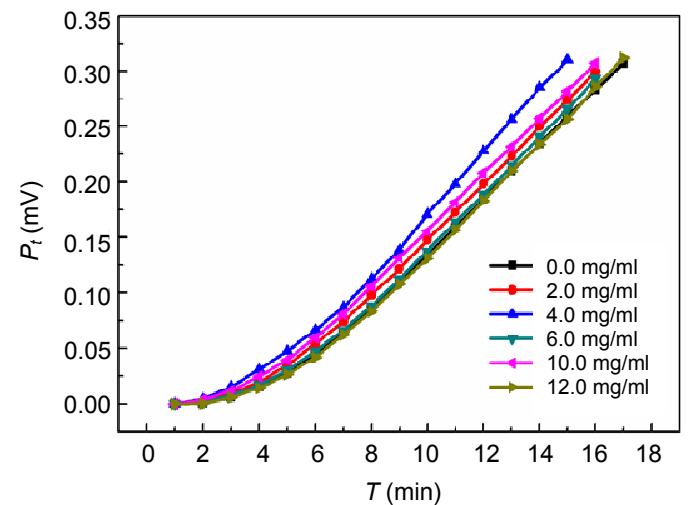

Fig. 3 Exponential phase of $E$. coli with different concentrations of Aconitum alkaloids

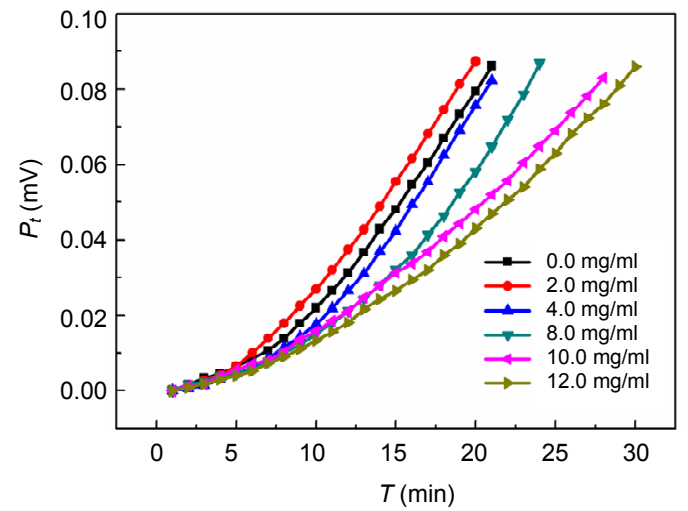

Fig. 4 Exponential phase of $S$. aureus with different concentrations of Aconitum alkaloids

growth rate constant, and $\beta$ is the bacterial static-rate constant. The integral of Eq. (1) is

$$
N_{t}=K /(1+\alpha \mathrm{e}-\mu t)
$$

where $K$ is the maximum density and $\alpha$ is integral constant. If the power produced by every bacterium is $P$, then $P N_{t}=K P /(1+\alpha \mathrm{e}-\mu t)$, making $P_{t}=P N_{t}$ and $P_{\mathrm{m}}=P K\left(P_{t}\right.$ is the power output at time $t$ and $P_{\mathrm{m}}$ is the maximum power output). This leads to the following relationship:

$$
P_{t}=P_{\mathrm{m}} /(1+\alpha \mathrm{e}-\mu t) .
$$

Eq. (3) is the logistic equation. If the values of $P_{t}$ and $t$ can be obtained from the bacterial growth curves, the rate constant $\mu$ can then be calculated.

The inhibition ratio, $I$, is an excellent index of the inhibition of different Glycyrrhiza extracts on the metabolism of E. coli. The inhibition ration can be defined as: 


$$
I=\left(\mu_{0}-\mu_{\mathrm{c}}\right) / \mu_{0} \times 100 \% \text {. }
$$

The enhancement ratio, $E$, is an excellent index of the inhibition of Aconitum alkaloids on E. coli and S. aureus, and can be defined as:

$$
E=\left(\mu_{\mathrm{c}}-\mu_{0}\right) / \mu_{0} \times 100 \%
$$

where $\mu_{0}$ and $\mu_{\mathrm{c}}$ are the growth rate constants of the bacteria without and with Aconitum alkaloids, respectively.

The corresponding values of $\mu, T_{\mathrm{m}}, P_{\mathrm{m}}, I, E$ and the calculated results are shown in Table 1.

\subsection{Relationships between growth rate constant $(\mu)$ and concentration $(c)$}

The relationships between $\mu$ and $c$ are demonstrated in Figs. 5 and 6 . The rate constant, $\mu$, of $E$. coli changed slightly with an increase in the concentration of Aconitum alkaloids. It could be inferred that Aconitum alkaloids had little influence on $E$. coli growth. Fig. 6 shows that $\mu$ for $S$. aureus growth increased with a low concentration of Aconitum alkaloids and decreased as the concentration was increased. This reveals that Aconitum alkaloids promoted $S$. aureus growth at low concentrations and inhibited growth at higher concentrations. When the concentration of Aconitum alkaloids was between 0 and $12 \mathrm{mg} / \mathrm{ml}$, the relationship between $\mu$ and $c$ was

$$
\begin{gathered}
\mu=0.0002 c^{3}-0.0050 c^{2}+0.0173 c+0.2452 \\
(r=0.9990) .
\end{gathered}
$$

According to Eqs. (4) and (5), the inhibitory (I) and enhancement $(E)$ ratios were calculated, as shown in Table 1. From the data, we concluded that Aconitum alkaloids had a minimal effect on $E$. coli growth and a potent antibacterial activity against $S$. aureus.

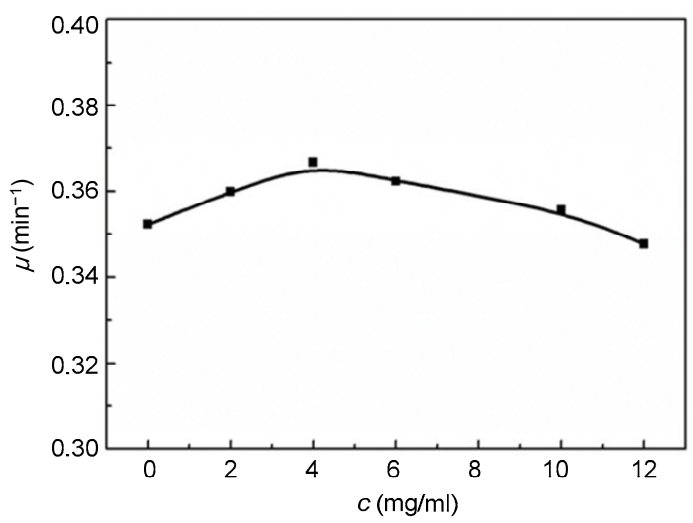

Fig. 5 Relationship between growth rate constant $(\mu)$ and concentration (c) of Aconitum alkaloids for $E$. coli

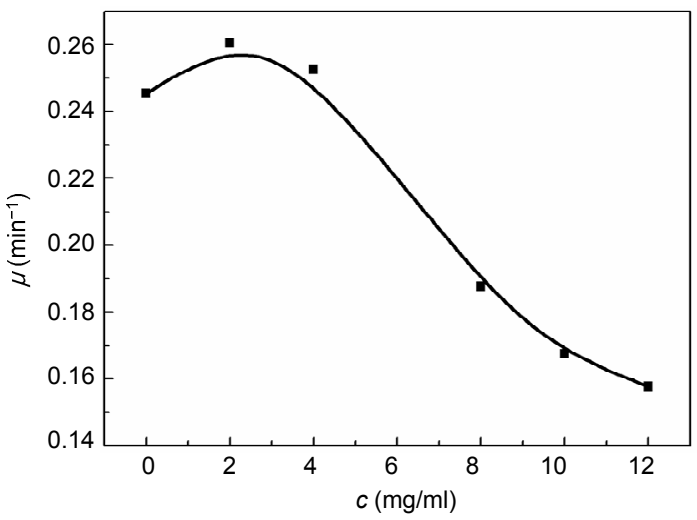

Fig. 6 Relationship between growth rate constant $(\mu)$ and concentration (c) of Aconitum alkaloids for $S$. aureus

Table 1 Parameters of $E$. coli and $S$. aureus growth at different concentrations of Aconitum alkaloids

\begin{tabular}{lccccccc}
\hline Bacteria & $c(\mathrm{mg} / \mathrm{ml})$ & $\mu\left(\mathrm{min}^{-1}\right)$ & $r$ & $T_{\mathrm{m}}(\mathrm{min})$ & $P_{\mathrm{m}}(\mathrm{mW})$ & $I(\%)$ & $E(\%)$ \\
\hline E. coli & 0 & 0.3522 & 0.9975 & 77 & 1.1346 & & 2.19 \\
& 2.0 & 0.3599 & 0.9973 & 78 & 1.1187 & & 4.12 \\
& 4.0 & 0.3667 & 0.9980 & 76 & 1.1507 & & 2.87 \\
& 6.0 & 0.3623 & 0.9976 & 75 & 1.1032 & & 0.99 \\
S. aureus & 10.0 & 0.3557 & 0.9972 & 77 & 1.1195 & & \\
& 12.0 & 0.3474 & 0.9973 & 78 & 1.1032 & 1.36 & \\
& 0 & 0.2455 & 0.9990 & 122 & 0.5414 & & \\
& 2.0 & 0.2604 & 0.9979 & 129 & 0.5045 & 5.50 & \\
& 4.0 & 0.2526 & 0.9991 & 145 & 0.5467 & 16.29 & 2.89 \\
& 8.0 & 0.1876 & 0.9988 & 154 & 0.5488 & 22.71 & \\
\end{tabular}

$c$ : concentration; $\mu$ : growth rate constant; $r$ : correlation coefficient; $T_{\mathrm{m}}$ : peak-time, $P_{\mathrm{m}}$ : maximum heat output; $I$ : inhibitory ratio; $E$ : enhancement ratio 


\subsection{Relationships between peak-time $\left(T_{\mathrm{m}}\right)$ and concentration $(c)$}

As seen in Table 1, Aconitum alkaloids had no effect on the first $T_{\mathrm{m}}$ of $E$. coli growth, while an increasing trend was observed in the values of $T_{\mathrm{m}}$ for $S$. aureus growth as $c$ was increased. This indicates that Aconitum alkaloids had a concentration-dependent inhibitory effect on S. aureus.

\section{Conclusions}

In this research, the microcalorimetric method was used to study the effect of different concentrations of Aconitum alkaloids on the growth of E. coli and $S$. aureus. By recording the heat output, the metabolic activity of the bacteria was evaluated, and the effect of extracts was investigated. By the kinetic and thermodynamic information from the microcalorimetric method, a series of kinetic parameters, such as the rate constant $\mu$, peak-time $T_{\mathrm{m}}$, maximum power output $P_{\mathrm{m}}$, inhibitory ratio $I$, and enhancement ratio $E$, were obtained. We also discussed the relationship between the growth rate constant $(\mu)$ and the concentration of Aconitum alkaloids (c). The rate constant of $E$. coli growth showed little change with increase in the concentration of Aconitum alkaloids. However, the growth rate constant of $S$. aureus increased and then decreased as the concentration of Aconitum alkaloids was increased. The increased concentration of Aconitum alkaloids changed the $T_{\mathrm{m}}$ of $E$. coli slightly, but the $T_{\mathrm{m}}$ of $S$. aureus was prolonged compared with the control. This indicated that the Aconitum alkaloid treatment slowed the growth and metabolism of $S$. aureus. We could draw the conclusion that Aconitum alkaloids had no effect on the growth of $E$. coli but a potential inhibitory effect on $S$. aureus.

This work has shown that microcalorimetry is a useful technique, which can be applied to the study of microbial growth. It also offered useful information for research and the application of the traditional herbal medicine RAL and its active ingredients.

\section{Compliance with ethics guidelines}

Yan-bin SHI, Lian LIU, Wei SHAO, Ting WEI, and Gui-mei LIN declare that they have no conflict of interest.

This article does not contain any studies with human or animal subjects performed by any of the authors.

\section{References}

Ameri, A., 1998. The effects of Aconitum alkaloids on the central nervous system. Prog. Neurobiol., 56(2):211-235. [doi:10.1016/S0301-0082(98)00037-9]

Chen, J.H., Lee, C.Y., Liau, B.C., et al., 2008. Determination of aconitine-type alkaloids as markers in fuzi (Aconitum carmichaeli) by $\mathrm{LC} /(+) \mathrm{ESI} / \mathrm{MS}^{3}$. J. Pharm. Biomed. Anal., 48(4):1105-1111. [doi:10.1016/j.jpba.2008.08.022]

Critter, S.A.M., Freitas, S.S., Airoldi, C., 2001. Calorimetry versus respirometry for the monitoring of microbial activity in a tropical soil. Appl. Soil Ecol., 18(3):217-227. [doi:10.1016/S0929-1393(01)00166-4]

Kong, W., Zhao, Y., Shan, L., et al., 2008. Microcalorimetric studies of the action on four organic acids in radix isatidis on the growth of microorganisms. Chin. J. Biotechnol., 24(4):646-650. [doi:10.1016/S1872-2075(08)60033-3]

Singhuber, J., Zhu, M., Prinz, S., et al., 2009. Aconitum in Traditional Chinese Medicine - a valuable drug or an unpredictable risk? J. Ethnopharmacol., 126(1):18-30. [doi:10.1016/j.jep.2009.07.031]

Wadsö, I., 1995. Microcalorimetric techniques for characterization of living cellular systems. Will there be any important practical applications? Thermochim. Acta, 269-270: 337-350. [doi:10.1016/0040-6031(95)02673-8]

Wadsö, I., 1997. Isothermal microcalorimetry near ambient temperature: an overview and discussion. Thermochim. Acta, 294(1):1-11. [doi:10.1016/S0040-6031(96)03136-X]

Wadsö, I., 2002. Isothermal microcalorimetry in applied biology. Thermochim. Acta, 394(1-2):305-311. [doi:10. 1016/S0040-6031(02)00263-0]

Wadsö, L., 2001. Isothermal microcalorimetry. Current problems and prospects. J. Therm. Anal. Calorim., 64(1): 75-84. [doi:10.1023/A:1011576710913]

Wang, J., van der Heijden, R., Spijksma, G., et al., 2009. Alkaloid profiling of the Chinese herbal medicine Fuzi by combination of matrix-assisted laser desorption ionization mass spectrometry with liquid chromatography-mass spectrometry. J. Chromatogr. A, 1216(11):2169-2178. [doi:10.1016/j.chroma.2008.11.077]

Wu, Y.W., Gao, W.Y., Xiao, X.H., et al., 2005. Calorimetric investigation of the effect of hydroxyanthraquinones in Rheum officinale Baill on Staphylococcus aureus growth. Thermochim. Acta, 429(2):167-170. [doi:10.1016/j.tca. 2005.03.008]

Xi, L., Yi, L., Jun, W., et al., 2002. Microcalorimetric study of Staphylococcus aureus growth affected by selenium compounds. Thermochim. Acta, 387(1):57-61. [doi:10. 1016/S0040-6031(01)00825-5]

Yan, D., Jin, C., Xiao, X., et al., 2007. Investigation of the effect of berberine alkaloids in Coptis chinensis Franch on Bacillus shigae growth by microcalorimetry. Sci. China Ser. B, 50(5):638-642. [doi:10.1007/s11426-0070094-9]

Yang, L., Xu, F., Sun, L., et al., 2008. Microcalorimetric 
studies on the antimicrobial actions of different cephalosporins. J. Therm. Anal. Calorim., 93(2):417-421. [doi:10.1007/s10973-007-8680-9]

Zhao, C., Li, M., Luo, Y., et al., 2006. Isolation and structural characterization of an immunostimulating polysaccharide from fuzi, Aconitum carmichaeli. Carbohyd. Res., 341(4): 485-491. [doi:10.1016/j.carres.2005.11.032]

\section{中文概要}

\section{题 目: 附子生物碱抗菌活性的微量热研究}

目 的: 研究附子生物碱对大肠杆菌和金黄色葡萄球菌生 长代谢作用的影响, 并对其抗菌活性进行评价。

创新点: 首次应用微量热的方法研究了大肠杆菌和金黄色 葡萄球菌在附子生物碱中的生长代谢作用, 并从
热力学角度对附子生物碱的抗菌活性进行了评价。 方 法: 微量量热仪绘制了 $37^{\circ} \mathrm{C}$ 时大肠杆菌和金黄色葡 萄球菌在不同浓度的附子生物碱作用下的热谱 曲线, 根据热动力学模型, 分别得到了生长速率 常数 $\mu$ 、抑制率 $I$ 、最大产热功率 $P_{\mathrm{m}}$ 以及最大产 热功率所对应的时间 $T_{\mathrm{m}}$ 等热动力学参数, 从热 动力学的角度探讨了附子生物碱对大肠杆菌和 金黄色葡萄球菌代谢作用的影响。

结 论: 实验结果显示, 附子生物碱对大肠杆菌的生长代 谢基本没有影响。但是对于金黄色葡萄球菌, 随 着附子生物碱浓度的增大, 其生长速率常数呈现 先升高后降低的趋势, 同时达峰时间也被延长, 说明附子生物碱对金黄色葡萄球菌存在潜在的 生长抑制作用。

关键词: 附子生物碱; 大肠杆菌; 金黄色葡萄球菌; 微热 量热法 